Proc. Indian Acad. Sci. (Chem. Sci.). Vol. 105. No. 3, June 1993. pp. 161-165.

(C) Printed in India.

\title{
Molecular structure of electron donor-acceptor complexes of metallotetraphenylporphyrins with trinitrobenzene
}

\author{
M PADMANABHAN, M DAMODARA POOJARI and V KRISHNAN* \\ Department of Inorganic and Physical Chemistry, Indjan Institute of Science, Bangalore \\ 560012, India
}

MS received 6 February 1993

\begin{abstract}
The metallotetraphenylporphyrins, MTPPs, where $\mathrm{M}=\mathrm{Co}(\mathrm{II}), \mathrm{Cu}(\mathrm{II})$ and $\mathrm{Ag}(\mathrm{II})$ form one to one molecular complexes in solution with 1,3,5-trinitrobenzene (TNB). The crystal structure of CoTPP.TNB. $2 \mathrm{CH}_{3} \mathrm{OH}$ revealed that the mean separation between the porphyrin and TNB planes is $3 \cdot 27 \AA$ and the centre of the aryl ting of TNB is displaced by $0.90 \AA$ from the centre of the porphyrin plane. Extended Huckel molecular orbital calculations suggest that the acceptor orbitals are predominantly nitro-group based rather than an aryl $\pi$ framework. The contribution of the metal orbitals in the donation is also seen as predicted by the structural data. Electrochemical redox measurements in solution provide evidence for charge-transfer stabilisation in these complexes.
\end{abstract}

Keywords. Electron donor-acceptor complexes; structural parameters; charge-transfer interactions; metallotetraphenylporphyrins; trinitrobenzene acceptor.

\section{Introduction}

The molecular architecture of metallotetraphenylporphyrins (MTPPs) furnishes ideal hosts for a variety of guest molecules to form clathrate structures (Byrn et al 1990 , 1992; Byrn and Strouse 1991). The nature of host-guest interactions is predominantly governed by Van der Waal forces. The metalloporphyrins are known to function as donors towards diverse organic $\pi$-acceptor molecules. Studies on these complexes reveal that the stabilising interaction between donor and acceptor is essentially of the $\pi-\pi$ type (Origg et al 1978; Scheidt et al 1978; Scheidt and Reed 1978; Pace et al 1982). A few available structural reports on the molecular complexes of metalloporphyrins indicate the possibility of metal orbital interaction, however, without any detail. Among the different organic $\pi$-acceptors, 1,3,5-trinitrobenzene (TNB) has been used for molecular complexation studies involving metalloporphyrins (Jeyakumar and Krishnan 1992). The solution structure of the molecular complex of mesotetratolylporphyrinato cobalt(II) with TNB derived from ${ }^{1} \mathrm{H}$ NMR data, revealed that the interaction between the donor and acceptor occur exclusively through the porphyrin periphery (Fulton and LaMar 1976). We report here the crystal and molecular structure of the molecular complex formed by CoTPP and TNB and demonstrate that besides porphyrin $\pi$-orbitals, the metal orbitals also contribute to the charge-transfer (CT) interaction.

\footnotetext{
* For correspondence
} 


\section{Experimental}

The complexes 5,10,15,20-tetraphenylporphyrinato cobalt(II), copper(II) and silver(II) were synthesised and purified according to published procedures (Rothemund and Menotti 1948). 1,3,5-trinitrobenzene was procured from BDH (England) and crystallised twice in benzene (m.p. $122^{\circ}$ ). All the solvents employed in this study are of spectral grade.

Crystals of molecular complexes of MTPP [(M = Co(II), Ni(II), $\mathrm{Cu}(\mathrm{II}), \mathrm{Zn}$ (II) and $\mathrm{Ag}(\mathrm{II})]$ and TNB of the composition (MTPP.TNB). $2 \mathrm{CH}_{3} \mathrm{OH}$ are grown by controlled evaporation of a solution consisting of an equimolar mixture of the metalloporphyrins and $\mathrm{TNB}$ in $\mathrm{CHCl}_{3}$ containing $\mathrm{CH}_{3} \mathrm{OH}$ under nitrogen atmosphere. Single-crystal $\mathrm{X}$-ray structure analysis has been carried out on (CoTPP.TNB). $2 \mathrm{CH}_{3} \mathrm{OH}$. Crystals of (CoTPP.TNB). $2 \mathrm{CH}_{3} \mathrm{OH}$ are orthorhombic, space group Pnnn with $a=6.544(2) \AA$, $b=24.295(5) \AA, c=14.818(3) \AA, V=2355.9 \AA^{3}, Z=2, D_{c}=1.34 \mathrm{~g} \mathrm{~cm}^{-3}$. Intensity data were collected on an Enraf-Nonius CAD-4 automated diffractometer with Mo--Ka radiations upto a 20 limit of $48^{\circ}$. The structure was solved by heavy atom method (Sheldrick 1976) and refined to present discrepancy indices $R$ and $R_{w}$ of 0.104 and 0.103 , respectively, for 918 reflections with $F_{0} \geqslant 5 \sigma\left(F_{0}\right)$.

The cyclovoltammetric studies have been carried out on a BAS-electrochemical system using a three-electrode assembly as described elsewhere (D'Souza and Krishnan 1992).

\section{Results and discussion}

The nature of disposition of TNB above CoTPP is shown in figure 1 and the bond distances and bond angles are given in table 1. The solvent $\mathrm{CH}_{3} \mathrm{OH}$ molecules are well isolated and are not in a position to interact with metal or any $\pi$-system. The CoTPP molecules possess a fair amount of planarity. The bond distances 1.97(1) $\AA$ and $1.96(1) \AA$ for $\mathrm{Co}-\mathrm{N}(1)$ and $\mathrm{Co}-\mathrm{N}(2)$ respectively are longer than that observed for $\mathrm{S}_{4}$-ruffled CoTPP but are closely comparable to the case in which the porphyrin core is planar (Scheidt and Lee 1987). The phenyl groups at the meso-carbons occupy alternative positions as a result of rotation about the $\mathrm{C}-\mathrm{C}$ single bond. Between the macrocycles translated along $a$, the planar TNB molecules are disordered about $b$, as demanded by 222 symmetry for a 1:1 composition in such a way that the centre of the aryl ring is shifted by $0.9 \AA$ along $c$. The crystal structure consists of such columnar stacks separated by disordered $\mathrm{CH}_{3} \mathrm{OH}$ molecules. The mean separation between the porphyrin and TNB planes is $3.27 \AA$. Studies on the structures of the other (MTPP.TNB). $2 \mathrm{CH}_{3} \mathrm{OH}$ complexes indicate that they are isomorphous with the cobalt complex.

The stabilisation in the MTPP.TNB complexes is explained based on HOMOLUMO interactions between the donor and acceptor. Extended Huckel type MO calculations have been performed (Gouterman 1978). These show that the low-lying vacant orbitals of TNB are a set of three $-\mathrm{NO}_{2}$ based orbitals, 3 , with $\mathrm{N}-\mathrm{O}$ antibonding character with their density mostly around the nitrogen atoms (figure 2 ). The orbitals 4 are ring based $\pi$-type donor orbitals of the metalloporphyrin; $a_{1 u}$ has density entirely on pyrrole $\alpha$ - and $\beta$-carbons while $a_{2 u}$ has it on nitrogens and meso carbon atoms. The preference of structures 1 and 2 becomes evident when one realises that the LUMOs of TNB are not aryl- but -- $\mathrm{NO}_{2}$ based. The structure $\underline{1}$ allows a significant 


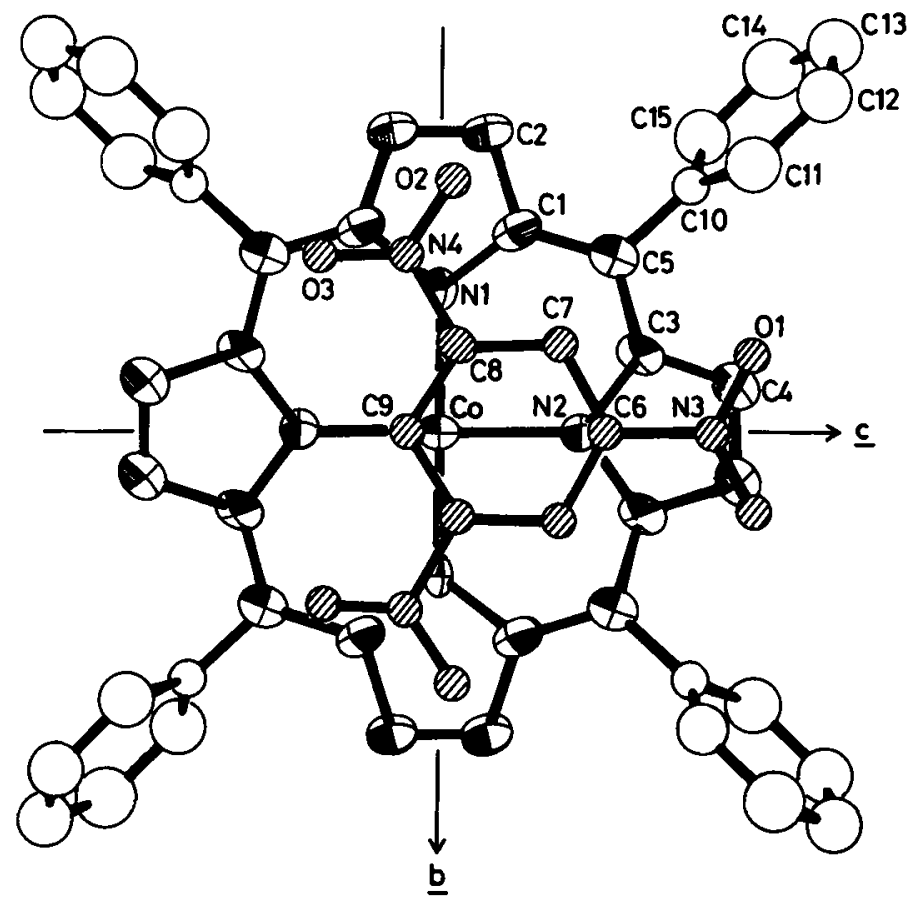

Figure 1. DRTEP drawing depicting the interaction between COTPP and TNB. The alternative positions of the phenyl carbon atoms and the disorder of TNB about $b$ are not shown for clarity.

Table 1. Bond distances $(\AA)$ and bond angles (degrees) in the CoTPP and TNB groups in CoTPP.TNB. $2 \mathrm{CH}_{3} \mathrm{OH}$.

\begin{tabular}{|c|c|c|c|}
\hline \multicolumn{4}{|l|}{ Bond distances } \\
\hline Co-N1 & $1.972(8)$ & $\mathrm{C} 5-\mathrm{Cl0}$ & $1 \cdot 49(1)$ \\
\hline Co-N2 & $1.963(8)$ & $\mathrm{C} 5-\mathrm{C} 16$ & $1.48(1)$ \\
\hline $\mathrm{N} 1-\mathrm{Cl}$ & $1 \cdot 386(9)$ & O1-N3 & $1.25(3)$ \\
\hline $\mathrm{Cl}-\mathrm{C} 2$ & $1.419(11)$ & N3-C6 & $1.43(5)$ \\
\hline $\mathrm{C} 2-\mathrm{C} 2$ & $1 \cdot 369(18)$ & C6-C7 & $1 \cdot 39(3)$ \\
\hline $\mathrm{C} 1-\mathrm{C} 5$ & $1.406(12)$ & $\mathrm{C} 7-\mathrm{C} 8$ & $1 \cdot 29(4)$ \\
\hline $\mathrm{C} 5-\mathrm{C} 3$ & $1.413(12)$ & C8-C9 & $1 \cdot 39(3)$ \\
\hline $\mathrm{C} 3-\mathrm{C} 4$ & $1.447(14)$ & C8-N4 & $1.55(3)$ \\
\hline $\mathrm{C} 4-\mathrm{C} 4$ & $1.447(21)$ & $\mathrm{N} 4-\mathrm{O} 2$ & $1 \cdot 15(4)$ \\
\hline $\mathrm{C} 3-\mathrm{N} 2$ & $1 \cdot 372(10)$ & $\mathrm{N} 4-\mathrm{O} 3$ & $1 \cdot 35(6)$ \\
\hline \multicolumn{4}{|l|}{ Bond angles } \\
\hline $\mathrm{N} 1-\mathrm{Co}-\mathrm{N} 2$ & $90 \cdot 0$ & $\mathrm{C} 6-\mathrm{N} 3-\mathrm{O} 1$ & $118(2)$ \\
\hline $\mathrm{Co}-\mathrm{N} 1-\mathrm{Cl}$ & $127 \cdot 7(5)$ & C7-C6-N3 & $119(2)$ \\
\hline $\mathrm{Co}-\mathrm{N} 2-\mathrm{C} 3$ & $127 \cdot 2(5)$ & $\mathrm{C} 8-\mathrm{C} 7-\mathrm{C} 6$ & $116(3)$ \\
\hline $\mathrm{C} 2-\mathrm{C} 1-\mathrm{N} 1$ & $109 \cdot 9(7)$ & $\mathrm{N} 4-\mathrm{C} 8-\mathrm{C} 7$ & $112(3)$ \\
\hline $\mathrm{C} 4-\mathrm{C} 3-\mathrm{N} 2$ & $108 \cdot 5(8)$ & $\mathrm{N} 4-\mathrm{C} 8-\mathrm{C} 9$ & $121(3)$ \\
\hline $\mathrm{C} 5-\mathrm{C} 3-\mathrm{N} 2$ & $126.5(9)$ & $\mathrm{C} 8-\mathrm{N} 4-\mathrm{O} 3$ & $109(4)$ \\
\hline $\mathrm{C} 4-\mathrm{C} 3-\mathrm{C} 5$ & $118.0(8)$ & $\mathrm{O} 2-\mathrm{N} 4-\mathrm{O} 3$ & $129(4)$ \\
\hline $\mathrm{C} 3-\mathrm{C} 5-\mathrm{Cl0}$ & $118 \cdot 7(7)$ & $\mathrm{C} 9-\mathrm{C} 8-\mathrm{C} 7$ & $127(3)$ \\
\hline $\mathrm{C} 5-\mathrm{C} 10-\mathrm{C} 11$ & $119 \cdot 1(3)$ & $\mathrm{O} 2-\mathrm{N} 4-\mathrm{O} 3$ & $129(4)$ \\
\hline C5-C:10-C15 & $120 \cdot 9(3)$ & $\mathrm{O} 2-\mathrm{N} 4-\mathrm{C} 8$ & $121(4)$ \\
\hline $\mathrm{C} 11-\mathrm{C} 10-\mathrm{C} 5$ & $119 \cdot 1(3)$ & & \\
\hline $\mathrm{C} 15 \cdot \mathrm{C} 10-\mathrm{C} 11$ & 120.0 & & \\
\hline
\end{tabular}




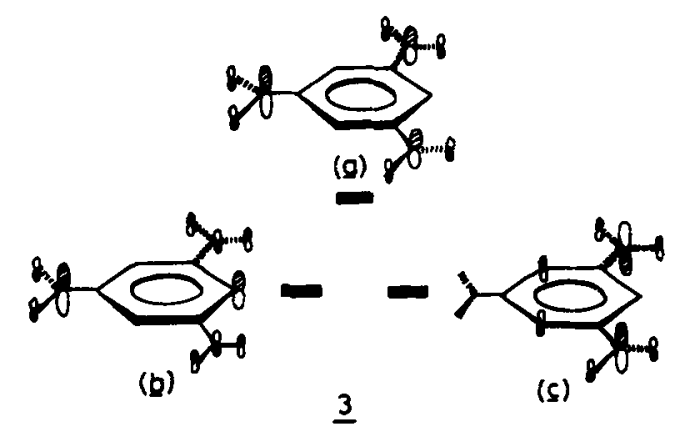

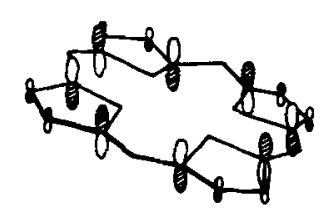

$a_{14}$

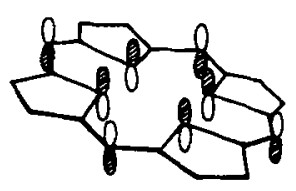

$a_{2 u}$

$\underline{4}$

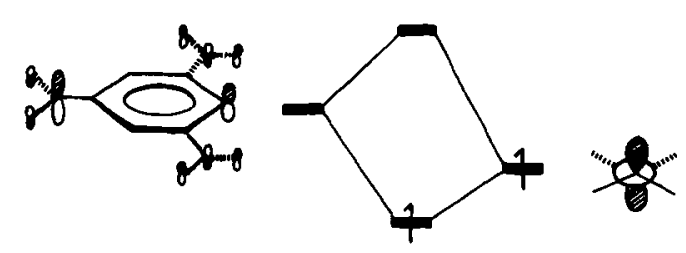

$\underline{5}$

Figure 2. HOMO-LUMO interactions between CoTPP and TNB.

overlap of $\underline{3} \underline{\mathrm{c}}$ with the HOMO $a_{1 u} ; \underline{3} \underline{a}$ and $\underline{3} \underline{b}$ with $a_{2 u}$. Both these interactions which lower the level of filled $a_{1 u}$ and $a_{2 u}$ contribute to the stability of the complex, the magnitude of which depends on the energy gap between the interacting orbitals and extent of overlap. The acceptor ability of TNB arises from these interactions through which its LUMOs get populated.

Another noteworthy point about structure 1 is the propensity of the LUMO $\underline{3 b}$ of TNB to directly interact with metal $d_{z^{2}}$ orbital. The LUMO has a significant coefficient (about $20 \%$ ) on the carbon which lies above the metal. So the geometry allows the carbon $p_{z}$ orbital to have an effective overlap with metal $d_{z^{2}}$ orbital of MTPP resulting in the lowering of the latter. This provides a rational explanation for the ESR results (Iwaizumi et al 1984). In the case of square-planar CoTPP of ${ }^{2} A_{1}$ configuration, the bonding combination of the above interaction $\underline{S}$ is singly occupied and would contribute to the overall stability of the molecular complex.

The electrochemical redox data of the molecular complex furnish some experimental evidence for the orbital interactions mentioned above. The addition of TNB to $\mathrm{CH}_{2} \mathrm{Cl}_{2}$ solution of MTPPs shifts the first ring oxidation potential of CuTPP and ZnTPP and the metal oxidation potential of CoTPP and AgTPP to more anodic side. The appreciable anodic shift $(80 \mathrm{mV})$ in the ring oxidation potential can be well explained by orbital interactions mentioned above which cause stabilisation of the 
$\pi$-orbitals $a_{1 u}$ and $a_{2 u}$. Similarly the anodic shift $(30 \mathrm{mV})$ observed for Co(II) TPP to Co(III)TPP ${ }^{+}$oxidation by removal of $d_{z^{2}}$ electron, in presence of TNB, can be considered to be originating from the stabilisation interaction 5 . This study provides the nature of CT stabilisation interaction between acceptor and metal orbitals and the influence of this in the electrochemical redox behaviour.

\section{Acknowledgements}

It is a pleasure to thank Prof $\mathrm{H}$ Manohar and Dr $\mathrm{J}$ Chandrasekhar for many helpful discussions. One of the authors (MP) thanks the Council of Scientific and Industrial Research, New Delhi, for award of a Pool Officership. We are grateful for support of this research from the Department of Science and Technology, New Delhi.

\section{References}

Byrn M P, Curtis C J, Goldberg I, Huang T, Hsiou Y, Khan S I, Swain P A, Tendrick S K, Terzis A and Strouse C E 1992 Mol. Cryst. Liq. Cryst. 211135

Byrn M P, Curtis C J, Goldberg I, Huang T, Hsiou Y, Khan S I, Swain P A. Tsurumi R and Strouse C E $1990 \mathrm{~J}$. Am. Chem. Soc. 1121865

Byrn M P and Strouse C E $1991 \mathrm{~J}$. Am. Chem. Soc. 113

D'Souza F and Krishnan V 1992 Photochem. Photobiol. 56145

Fulton G P and LaMar G M $1976 \mathrm{~J}$. Am. Chem. Soc. 982124

Gouterman M 1978 The porphyrins (ed.) D Dolphin (New York: Academic Press) vol. 3

Iwaizumi M, Ohba Y, lida H and Hirayama M 1984 Inorg. Chim. Acta 8247

Jeyakumar D and Krishnan V 1992 Spectrochim. Acta A48 1671, and references therein

Origg R, Trocha-Grimshaw J and King I J $1978 \mathrm{~J}$. Chem. Soc., Chem. Commun. 571

Pace L J, Vlman A and Ibers J A 1982 Inorg. Chem. 211999

Rothemund P and Menotti A R 1948 J. Am. Chem. Soc. 701808

Scheidt W R, Kastner M E and Hatano K 1978 Inorg. Chem. 171706

Scheidt W R and Lee Y 1987 Struct. Bonding 641

Scheidt W R and Reed C A 1978 Inorg. Chem. 17710

Sheldrick G M 1976 SHELX 76. Program for crystal structure determinations, University of Göttingen, Germany 